\title{
Deletion of a Neuronal Drp1 Activator Protects against Cerebral Ischemia
}

\author{
${ }^{\circledR}$ Kyle H. Flippo, ${ }^{1 *}$ Zhihong Lin, ${ }^{1 *}$ Audrey S. Dickey, ${ }^{2}$ Xinchang Zhou, ${ }^{3}$ Nirav A. Dhanesha, ${ }^{4}$ \\ Grant C. Walters, ${ }^{1}$ Yujia Liu, ${ }^{1}$ Ronald A. Merrill, ${ }^{1}$ Robert Meller, ${ }^{5}$ Roger P. Simon, ${ }^{5,6}$ Anil K. Chauhan, ${ }^{4}$ \\ ${ }^{\circ}$ Yuriy M. Usachev, ${ }^{1}$ and ${ }^{1}$ Stefan Strack ${ }^{1}$ \\ ${ }^{1}$ Department of Neuroscience and Pharmacology and Iowa Neuroscience Institute, University of Iowa, Iowa City, Iowa 52242, ${ }^{2}$ Department of \\ Neurology, Duke University, Durham, North Carolina 27708, ${ }^{3}$ Clinical Vector Core, Children's Hospital of Philadelphia, Philadelphia, Pennsylvania \\ 19104, ${ }^{4}$ Department of Internal Medicine, University of Iowa, Iowa City, Iowa 52242, ${ }^{5}$ Neuroscience Institute, Morehouse School of Medicine, \\ Atlanta, Georgia 30310, and ${ }^{6}$ Department of Medicine, Morehouse School of Medicine, Atlanta, Georgia 30310
}

Mitochondrial fission catalyzed by dynamin-related protein 1 (Drp1) is necessary for mitochondrial biogenesis and maintenance of healthy mitochondria. However, excessive fission has been associated with multiple neurodegenerative disorders, and we recently reported that mice with smaller mitochondria are sensitized to ischemic stroke injury. Although pharmacological Drp1 inhibition has been put forward as neuroprotective, the specificity and mechanism of the inhibitor used is controversial. Here, we provide genetic evidence that Drp1 inhibition is neuroprotective. Drp1 is activated by dephosphorylation of an inhibitory phosphorylation site, Ser637. We identify B $\beta 2$, a mitochondria-localized protein phosphatase 2A (PP2A) regulatory subunit, as a neuron-specific Drp1 activator in vivo. B $\beta 2 \mathrm{KO}$ mice of both sexes display elongated mitochondria in neurons and are protected from cerebral ischemic injury. Functionally, deletion of B $\beta 2$ and maintained Drp1 Ser637 phosphorylation improved mitochondrial respiratory capacity, $\mathrm{Ca}^{2+}$ homeostasis, and attenuated superoxide production in response to ischemia and excitotoxicity in vitro and ex vivo. Last, deletion of $\mathrm{B} \beta 2$ rescued excessive stroke damage associated with dephosphorylation of Drp1 S637 and mitochondrial fission. These results indicate that the state of mitochondrial connectivity and PP2A/B $\beta 2$-mediated dephosphorylation of Drp1 play a critical role in determining the severity of cerebral ischemic injury. Therefore, $\mathrm{B} \beta 2$ may represent a target for prophylactic neuroprotective therapy in populations at high risk of stroke.

Key words: cerebral ischemia; Drp1; mitochondrial fission; mitochondrial fusion; PP2A; stroke

Significance Statement

With recent advances in clinical practice including mechanical thrombectomy up to $24 \mathrm{~h}$ after the ischemic event, there is resurgent interest in neuroprotective stroke therapies. In this study, we demonstrate reduced stroke damage in the brain of mice lacking the $\mathrm{B} \beta 2$ regulatory subunit of protein phosphatase $2 \mathrm{~A}$, which we have shown previously acts as a positive regulator of the mitochondrial fission enzyme dynamin-related protein 1 (Drp1). Importantly, we provide evidence that deletion of $\mathrm{B} \beta 2$ can rescue excessive ischemic damage in mice lacking the mitochondrial PKA scaffold AKAP1, apparently via opposing effects on Drp1 S637 phosphorylation. These results highlight reversible phosphorylation in bidirectional regulation of Drp1 activity and identify B $\beta 2$ as a potential pharmacological target to protect the brain from stroke injury.

\section{Introduction}

$\mathrm{B} \beta 2$ is a member of a large family of regulatory subunits of the protein phosphatase $2 \mathrm{~A}(\mathrm{PP} 2 \mathrm{~A})$ heterotrimer complex, which

\footnotetext{
Received Aug. 7, 2019; revised Feb. 25, 2020; accepted Feb. 26, 2020.

Author contributions: K.H.F. and S.S. designed research; K.H.F., Z.L., A.S.D., N.A.D., G.C.W., Y.L., R.A.M., R.M., and R.P.S. performed research; A.S.D., X.Z., R.M., R.P.S., A.K.C., Y.M.U., and S.S. contributed unpublished reagents/ analytic tools; K.H.F., Z.L., A.S.D., R.A.M., and Y.M.U. analyzed data; K.H.F., Y.M.U., and S.S. wrote the paper.

This work was supported by National Institutes of Health Grants NS056244, NS087908 to S.S., NS087068 and NS096246 to Y.M.U., and HL139926, NS109910 to A.K.C.; by American Heart Association Grant $18 E I A 33900009$ to A. K.C., by the Roy J. Carver Charitable Trust and lowa Neuroscience Institute (S.S., Y.M.U.), and by these facilities of the Carver College of Medicine: Genomics Division, Viral Vector Core, and Central Microscopy Core.
}

also contains a scaffolding and catalytic subunit. An alternative splice product of the gene $P P P 2 R 2 B$ (Fig. 1-1A, available at https://doi.org/10.1523/JNEUROSCI.1926-19.2020.f1-1), a trinucleotide expansion in which causes spinocerebellar ataxia type 12

*K.H.F. and Z.L. contributed equally to this work.

The authors declare no competing financial interests.

Correspondence should be addressed to Stefan Strack at stefan-strack@uiowa.edu or Yuriy M. Usachev at yuriy-usachev@uiowa.edu.

https://doi.org/10.1523/JNEUROSCI.1926-19.2020

Copyright $\odot 2020$ the authors 
(Holmes et al., 1999), $\mathrm{B} \beta 2$ expression is neuron specific but widespread throughout the nervous system (Dagda et al., 2003). During neuronal stress in vitro, $\mathrm{B} \beta 2$ targets $\mathrm{PP} 2 \mathrm{~A}$ to the outer mitochondrial membrane, promoting mitochondrial fission and cell death through dephosphorylation of the mitochondrial fission enzyme dynamin-related protein 1 (Drp1) at the inhibitory phosphorylation site serine 637 (numbering according to human splice isoform 1; Dagda et al., 2003, 2005, 2008; Merrill et al., 2013).

As we have reported recently, phosphoregulation of Drp1S637 plays an important role in determining ischemic sensitivity (Flippo et al., 2018). Deletion of the outer mitochondrial scaffolding protein A-kinase anchoring protein 1 (AKAP1) in mice reduced inhibitory phosphorylation of Drp1-S637 at the mitochondria, promoted Drp1 localization to mitochondria and mitochondrial fragmentation, and exacerbated cerebral ischemic damage following transient middle cerebral artery occlusion (MCAO; Flippo et al., 2018). These results are in line with prior work, showing that pharmacological inhibition of Drp1 with the small molecule mdivi-1 is protective in rodent models of ischemic stroke (Grohm et al., 2012; Zhao et al., 2014; Li et al., 2015). However, the specificity, efficacy, and mechanism by which mdivi-1 protects against ischemic damage has recently been challenged (Bordt et al., 2017). Therefore, whether inhibition of Drp1 is protective against stroke in vivo remains an open question.

To address this question, we have deleted $\mathrm{B} \beta 2$ in mice and examined the role of inhibitory Drp1 S637 phosphorylation in ischemic sensitivity in vivo. We found that deletion of even a single $\mathrm{B} \beta 2$ allele significantly decreased infarct volume $24 \mathrm{~h}$ after transient MCAO. Furthermore, loss of $\mathrm{B} \beta 2$ promoted mitochondrial elongation specifically in neurons without altering total mitochondrial mass. Consistently, deletion of $\mathrm{B} \beta 2$ decreased localization of the catalytic subunit of PP2A to the mitochondria, leading to hyperphosphorylation of mitochondrial Drp1 at S637 due to unopposed AKAP1/PKA. Mechanistically, we found that deletion of $\mathrm{B} \beta 2$ delays calcium dysregulation in the CA1 region of the hippocampus after challenge with oxygen-glucose deprivation (OGD). Furthermore, OGD failed to induce a surge in superoxide production in hippocampal slices from $\mathrm{B} \beta 2 \mathrm{KO}$ mice. To examine cell autonomy, we cultured hippocampal neurons from mice lacking $\mathrm{B} \beta 2$ and observed similar delayed $\mathrm{Ca}^{2+}$ excitotoxicity and decreased superoxide production in response to glutamate excitotoxicity. Consistent with resilience to metabolic stress, respirometry revealed increased spare respiratory capacity in $\mathrm{B} \beta 2 \mathrm{KO}$ neurons. Introducing a phosphomimetic Drp1 mutant into hippocampal neurons recapitulated all outcome improvements observed in neurons lacking $\mathrm{B} \beta 2$, establishing Drp1 Ser637 as a critical substrate in ischemic sensitization by outer-mitochondrial PP2A. Last, deleting B $\beta 2$ in mice lacking AKAP1 rescued worsened stroke outcomes observed in mice that only lack AKAP1, indicating convergent mechanisms in vivo.

\section{Materials and Methods}

Animals

All animal work was performed in accordance with the guidelines of the animal ethics committee of the University of Iowa. Mice were grouphoused in a colony maintained with a standard $12 \mathrm{~h}$ light/dark cycle and given food and water ad libitum. Experiments were performed on agematched mice of both sexes except for MCAO and TEM experiments in which only male mice were used. Experiments were conducted according to the Guide for the Care and Use of Laboratory Animals, as adopted by the National Institutes of Health, and with approval of the University of Iowa, Institutional Animal Care and Use Committee.

In our $\mathrm{B} \beta 2$-null mice, the $\mathrm{N}$-terminal 24 aa (exon 1 ) of $\mathrm{B} \beta 2$ have been replaced with the coding sequence for $\beta$ gal (lacZ) and a neomycin cassette surrounded by two loxP sites followed by a polyadenylation signal to terminate the transcript. This selectively deletes the $\mathrm{B} \beta 2$ splice variant. Targeted ES cells were injected into C57Bl/6 blastocysts, which were implanted into pseudo-pregnant ICR strain females to create chimeric mice (Gene Targeting Core Facility; Baoli Yang, director). Once germline transmission was established, a $\mathrm{B} \beta 2+/-$ mouse was crossed with a transgenic mouse carrying the EIIa-Cre gene (which expresses Cre recombinase after fertilization) to remove the neomycin cassette and the offspring were backcrossed to C57BL/6 mice to generate $\mathrm{B} \beta 2+/-$ mice without the EIIa-Cre transgene. To distinguish $\mathrm{B} \beta 2+/+,+/-$, and $-1-$ by PCR, the following PCR primers were used: ACT CCA GTG CAA CAA CCG GCA CTC C (Rev), CCT TTG GAA GAT GAA ATG CTT CTC TCG (F 1), and GGC GCG CCT TAA TTA AGG ATC CTG C (F 2). The expected PCR product size from wild-type (WT) mice is $\sim 600 \mathrm{bp}$, whereas the null allele gives rise to a product of $\sim 400 \mathrm{bp}$.

\section{Antibodies and reagents}

A mouse monoclonal antibody recognizing $\mathrm{B} \beta 2$ was generated at the University of Iowa Hybridoma facility. Briefly, a peptide corresponding to part of the unique N-terminus of $\mathrm{B} \beta 2$ (aa 3-20, CFSRYLPYIFRPPNTILS) was synthesized and conjugated via the $\mathrm{N}$-terminal Cys to maleimideactivated bovine serum albumin (ThermoFisher). Hybridomas were isolated and screened by ELISA for antibody secretion according to standard protocols. The rabbit polyclonal antibody specific for $\mathrm{B} \beta 1$ was described previously (Strack et al., 1998). The rabbit polyclonal antibody directed against MnSOD was a kind gift from Frederick Domann (University of Iowa). The following commercially available antibodies were used: rabbit anti-phospho-Ser637 Drp1 (Cell Signaling Technology), mouse anti-PP2A/C, mouse anti-Drp1, mouse anti-Opa1, mouse antiMAP2B (BD Transduction Laboratories), mouse anti-beta-tubulin (Developmental Studies Hybridoma Bank, University of Iowa), rabbit anti-TOM20, rabbit anti-TOM40 (Santa Cruz Biotechnology), mouse anti-Hsp60 (Proteintech), mouse anti-OXPHOS, rabbit anti-VDAC (Abcam), infrared fluorophore-coupled secondary antibodies (Licor), and HRP-conjugated secondary antibodies (PerkinElmer). Hoechst 33342, dihydroethidium (DHE), and Lipofectamine 2000 were from Invitrogen. All other reagents were obtained from Sigma-Aldrich.

\section{Viral vectors}

AAV5-CAG-GCaMP6f-WPRE was a kind gift from Dr. Catherine Marcinkiewcz and was used as described in the Stereotactic injection section. Lentivirus expressing phosphomimetic Drp1 (S637D) and outer mitochondria-targeted GFP (Mas70-GFP) were described previously (Flippo et al., 2018). Vectors express the major neuronal Drp1 splice variant, which includes all three alternative coding exons $(3,16$, and 17 ; Uo et al., 2009; Strack et al., 2013). To replace endogenous with mutant Drp1, the lentivirus also expresses a Drp1-targeting shRNA from the H1 promotor inserted into the MfeI site of the vector pFIV3.1-CAGmcs. Virus was generated at the University of Iowa Viral Vector Core. Viral infection of cortical and hippocampal cultures was performed at 7 DIV by removing one-half of the media volume from each well and replacing with NB-A media containing virus (1:100-1:250 dilution for respirometry, 1:1000 for $\mathrm{Ca}^{2+} / \mathrm{DHE}$ imaging). After $6 \mathrm{~h}$ incubation, virus-containing media was replaced with conditioned NB-A media.

Middle cerebral artery occlusion

This procedure was performed at the University of Iowa and at Legacy Research, both of which are accredited by the Association for Assessment and Accreditation of Laboratory Animal Care in accordance with protocols approved by the Institutional Animal Care and Use Committee of each facility, as well as the principles outlined in the National Institute of Health Guide for the Care and Use of Laboratory animals. A murine focal ischemia model was used to determine the potential protective effects of $\mathrm{B} \beta 2$ knock-out. In this model, a $45 \mathrm{~min}$ period of middle cerebral artery occlusion results in significant infarction of the ipsilateral hemisphere, as 
determined by staining with the vital dye triphenyltetrazolium chloride (TTC). Adult mice were anesthetized using 5\% isoflurane, and then maintained at $2 \%$ isoflurane. Depth of anesthesia was determined by periodic (every $10 \mathrm{~min}$ ) assessment of respiration and pinch withdrawal reflex. Brain temperature was measured using a temporalis muscleimplanted thermocouple (Omega) and controlled within the range of $37 \pm 0.5^{\circ} \mathrm{C}$. The middle cerebral artery (MCA) was occluded for a $45 \mathrm{~min}$ period by threading a silicone-coated 6-0 monofilament nylon surgical suture through the external carotid to the internal carotid, and blocking its bifurcation into the MCA and anterior cerebral artery (Traystman, 2003). Achievement of ischemia and reperfusion was confirmed by monitoring regional cerebral blood flow $(\mathrm{CBF})$ in the area of the right middle cerebral artery, recording CBF 2 min after insertion and $5 \mathrm{~min}$ after removal of the suture. CBF was monitored through a disposable microtip fiber-optic probe (diameter $0.5 \mathrm{~mm}$ ) connected through a Master Probe to a laser Doppler computerized main unit (PF5001, Perimed) and analyzed using PSW Perisoft 2.5 (Kawano et al., 2006) for each mouse, which showed that regional cerebral blood flow was reduced by $70-90 \%$ (Fig. $2-1$, available at https://doi.org/10.1523/ JNEUROSCI.1926-19.2020.f2-1).

Infarct volume was assessed $24 \mathrm{~h}$ following MCAO using a TTC method (Cheng et al., 1996). Animals were killed by isoflurane overdose, brains were rapidly removed, sectioned coronally at $2 \mathrm{~mm}$ intervals using a mouse Brain Matrix (Roboz Surgical Instrument) and immersed in TTC (2\%) at $37^{\circ} \mathrm{C}$ for $20 \mathrm{~min}$, followed by formaldehyde (4\%) for $15 \mathrm{~min}$. Sections were scanned, and infarct areas were measured using Image (NIH) software. Scans of all brain slices were performed in order, such that any spurious, artefactual variations in dye intensity could be detected by reference to the previous and next slice. To correct for brain swelling due to edema after ischemia the corrected total infarct volume (\%) was calculated according to: Corrected infarct volume (\%) $=\{[$ volume of contralateral hemisphere - (volume of ipsilateral hemispherevolume of infarct)] $\}$ /Volume of contralateral hemisphere $\times 100$. MCAO surgery and infarct area determination were performed blinded, but with genotypes interleaved.

\section{TEM of brain mitochondria}

Six adult mice (2/genotype) were anesthetized with Nembutal $(50 \mathrm{mg} /$ $\mathrm{kg}$ ) and transcardially perfused with PBS, $\mathrm{pH} 7.4$, followed by $4 \%$ paraformaldehyde, and their brains removed. Samples were postfixed overnight in $2.5 \%$ glutaraldehyde, and $100 \mathrm{~mm}$ sodium cacodylate, $\mathrm{pH} 7.2$, and cut at $100 \mathrm{~mm}$ using a vibratome before embedding flat in epoxy resin. Microscopy was performed blinded with a transmission electron microscope (JEOL 1230 TEM) equipped with a CCD camera. Analysis was performed using ImageJ to measure the size and shape of each mitochondrion blind to genotype.

\section{Subcellular fractionation}

Prior to forebrain isolation, mice anesthetized with ketamine/xylazine were perfused with an ice-cold PBS plus phosphatase inhibitor cocktail [0.1 mм ammonium molybdate, 2 mm EDTA, 2 mм EGTA, 50 mм NaF, $2 \mathrm{~mm}$ sodium pervanadate (made fresh), $10 \mathrm{~mm}$ sodium pyrophosphate, $50 \mathrm{~nm}$ Calyculin A, $2 \mu \mathrm{M}$ FK506]. Forebrain tissue was isolated and homogenized in isolation buffer [IB; $225 \mathrm{~mm}$ mannitol, $75 \mathrm{~mm}$ sucrose, 1 mM EGTA, 1 mм EDTA, 5 mм HEPES-KOH, 2 mm sodium pervanadate (made fresh), $10 \mathrm{~mm}$ sodium pyrophosphate, $20 \mathrm{~mm} \beta$-glycerophosphate, $1 \mathrm{~mm}$ benzamidine, leupeptin (1:2000), $100 \mathrm{~nm}$ microcystin-LR, 2 $\mu \mathrm{M}$ FK506, PMSF (1:250), pH 7.2] using a power homogenizer. One hundred microliters of homogenate sample was taken and diluted in $4 \times$ sample buffer.

A mitochondria-enriched fraction was then prepared similar to previously described (Wang et al., 2011). Briefly, the remaining homogenate was then centrifuged at $1100 \times g$ for $2 \mathrm{~min}$ at $4^{\circ} \mathrm{C}$ keeping the supernatant [post-nuclear supernatant (PNS)] and resuspending the pellet in $4 \times$ sample buffer (nuclear fraction). A $100 \mu \mathrm{l}$ sample of PNS was taken and diluted in $4 \times$ sample buffer. The remaining PNS was centrifuged at $17,000 \times g$ for $15 \mathrm{~min}$ at $4^{\circ} \mathrm{C}$. The supernatant from this step was further centrifuged at $80,000 \times g$ for $60 \mathrm{~min}$ to obtain a cytosolic fraction while the pellet was resuspended in IB and centrifuged over a $9 / 10 \%$ Percoll interface at $18,500 \times g$ for $15 \mathrm{~min}$ to obtain a mitochondria-enriched pellet. The mitochondria-enriched pellet was resuspended in IB and centrifuged at $10,000 \times g$ for $5 \mathrm{~min}$. The pellet was resuspended in $4 \times$ sample buffer as the mitochondrial fraction.

\section{Stereotactic injection}

Adult mice (12-14 weeks old) were anesthetized with $2-3 \%$ isoflurane and placed on a stereotaxic frame. Heat pads were used through the duration of the surgery to keep the body temperature stable. Eye ointment was applied to keep the eyes from drying. An incision was made to the skin to expose the skull after asepsis with Betadine and medical alcohol was applied. For viral injection, a craniotomy was made and a $1 \mu \mathrm{L}$ Hamilton syringe was slowly inserted into the target region. Virus (0.4$0.6 \mu \mathrm{l} ; 2.3 \times 10^{13} \mathrm{vg} / \mathrm{ml}$ titer) was injected with an injection speed of $0.02 \mu \mathrm{l} / \mathrm{min}$. For ex vivo $\mathrm{Ca}^{2+}$ imaging, AAV5-CAG-GCaMP6f-WPRE virus was unilaterally injected into the CA1 region of the hippocampus (AP: -1.95 , ML: $+1.25, \mathrm{DV}:-1.2$ ) of $\mathrm{WT}$ and $\mathrm{B} \beta 2 \mathrm{KO}$ mice. Animals were allowed to recover for 3 weeks after surgery before harvesting brains for acute slice preparation.

\section{Acute slice preparation}

Brains were rapidly dissected from mice following decapitation and placed in ice-cold $\mathrm{N}$-methyl-D-glucamine (NMDG)-HEPES artificial CSF (aCSF) cutting solution (in mM): $92 \mathrm{NMDG}, 2.5 \mathrm{KCl}, 1.25 \mathrm{NaH}_{2} \mathrm{PO}_{4}, 30$ $\mathrm{NaHCO}_{3}, 20$ HEPES, 25 glucose, 2 thiourea, $5 \mathrm{Na}$-ascorbate, 3 Na-pyruvate, $0.5 \mathrm{CaCl}_{2}$, and $10 \mathrm{MgSO}_{4}$. Brains were then sliced in $300 \mu \mathrm{m} \mathrm{sec}-$ tions on a Leica VT-1000S vibratome (Leica Microsystems), placed in $34^{\circ}$ C NMDG-HEPES aCSF cutting solution for $10-15 \mathrm{~min}$, and then moved to $25^{\circ} \mathrm{C}$ recovery buffer (in mM: $92 \mathrm{NaCl}, 2.5 \mathrm{KCl}, 1.25 \mathrm{NaH}_{2} \mathrm{PO}_{4}, 30$ $\mathrm{NaHCO}_{3}, 20$ HEPES, 25 glucose, 2 thiourea, $5 \mathrm{Na}$-ascorbate, $3 \mathrm{Na}$-pyruvate, $0.5 \mathrm{CaCl}_{2}$, and $10 \mathrm{MgSO}_{4}$.) for at least $1 \mathrm{~h}$ before recording.

\section{Two-photon $\mathrm{Ca}^{2+}$ imaging in slices}

For $\mathrm{Ca}^{2+}$ imaging, slices were placed in a recording chamber on the stage of an upright Olympus FVMPE RS Multiphoton Microscope and imaged using $\lambda_{\mathrm{Ex}}=935 \mathrm{~nm}$ with a $20 \times$ water-immersion objective (NA = 1.0; Olympus, XLUMFLN) for changes in GCaMP6f fluorescence during perfusion with oxygenated $\left(95 \% \mathrm{O}_{2}, 5 \% \mathrm{CO}_{2}\right)$ recording solution (in mM: $92 \mathrm{NaCl}, 2.5 \mathrm{KCl}, 1.25 \mathrm{NaH}_{2} \mathrm{PO}_{4}, 30 \mathrm{NaHCO}_{3}, 25$ glucose, 2 $\mathrm{CaCl}_{2}$, and $2 \mathrm{MgSO}_{4}$.) for $5 \mathrm{~min}$ followed by perfusion with oxygen and glucose deprived $\left(95 \% \mathrm{~N}_{2}, 5 \% \mathrm{CO}_{2}\right)$ recording solution (in mM: $92 \mathrm{NaCl}$, $2.5 \mathrm{KCl}, 1.25 \mathrm{NaH}_{2} \mathrm{PO}_{4}, 30 \mathrm{NaHCO}_{3}, 0$ glucose, 25 sucrose, $2 \mathrm{CaCl}_{2}$, and $2 \mathrm{MgSO}_{4}$.) for $30 \mathrm{~min}$. Image stacks were stabilized using the TurboReg plugin included with the Fiji distribution of ImageJ and fluorescence was quantified for the soma of individual cells following creation of a mask using the ImageJ multimeasure analysis function. For those neurons that produced delayed $\mathrm{Ca}^{2+}$ deregulation (DCD), latent period duration was measured as follows: the raw trace recording was smoothed using a running average protocol (GraphPad Prism 8); the first derivative to the smoothed trace was then calculated and plotted as a function of time; the times corresponding to onset of perfusion with oxygen and glucose deprived recording solution response and peak DCD slope were determined with the duration of time in minutes between the two calculated as the latent period duration.

\section{Superoxide imaging in hippocampal slices}

During incubation in recovery buffer at room temperature acute slices were incubated with $20 \mu \mathrm{M}$ DHE for $1.5 \mathrm{~h}$ prior to imaging. For superoxide imaging slices were placed in a recording chamber on the stage of an Olympus FVMPE RS Multiphoton Microscope and imaged using $\lambda_{\mathrm{Ex}}=$ $760 \mathrm{~nm}$ with a $20 \times$ water-immersion objective $(\mathrm{NA}=1.0)$ for changes in DHE fluorescence during perfusion with oxygenated $\left(95 \% \mathrm{O}_{2}, 5 \% \mathrm{CO}_{2}\right)$ recording solution (in mM: $92 \mathrm{NaCl}, 2.5 \mathrm{KCl}, 1.25 \mathrm{NaH}_{2} \mathrm{PO}_{4}, 30$ $\mathrm{NaHCO}_{3}, 25$ glucose, $2 \mathrm{CaCl}_{2}$, and $\left.2 \mathrm{MgSO}_{4} ; 0.02 \mathrm{DHE}\right)$ followed by perfusion with oxygen and glucose deprived $\left(95 \% \mathrm{~N}_{2}, 5 \% \mathrm{CO}_{2}\right)$ recording solution (in mM: $92 \mathrm{NaCl}, 2.5 \mathrm{KCl}, 1.25 \mathrm{NaH}_{2} \mathrm{PO}_{4}, 30 \mathrm{NaHCO}_{3}, 0$ glucose, 25 sucrose, $2 \mathrm{CaCl}_{2}$, and $2 \mathrm{MgSO}_{4} ; 0.02 \mathrm{DHE}$ ) for 5 and $30 \mathrm{~min}$, respectively. Image stacks were aligned using the TurboReg plugin for Fiji/ImageJ and fluorescence was quantified for the soma 
of individual cells following creation of a mask using the ImageJ multimeasure analysis function. Rate of DHE oxidation $(\Delta \mathrm{Fl} / \mathrm{min}$, where $\Delta \mathrm{Fl}$ is change in DHE fluorescence intensity as a function of time) was calculated during constant perfusion of oxygen and glucose deprived recording solution.

\section{Primary neuronal cultures}

Primary mouse cultures of cortical and hippocampal neurons were prepared from P0-P1 neonates. Brains were removed from neonates and dissected first removing dura, dissecting hippocampi, and finally cortex. Tissue was stored in ice-cold Neurobasal Adult (NB-A; Invitrogen) media until processed. Tissue was incubated in HEPES buffered saline (HBS; $10 \mathrm{~mm}$ HEPES, $150 \mathrm{~mm} \mathrm{NaCl}, \mathrm{pH} 7.4, \mathrm{Ca}^{2+} / \mathrm{Mg}^{2+}$-free), containing trypsin $(0.03 \%)$ at $37^{\circ} \mathrm{C}$ for $20 \mathrm{~min}$. The tissues were washed three times with $\mathrm{Ca}^{2+} / \mathrm{Mg}^{2+}$-free HBS before cells were dissociated by trituration. Cells were plated in NB-A complete [NB-A supplemented with B-27 $(1.5 \times)$, glutamine $(0.6 \mathrm{~mm})$, and gentamycin $(1: 10,000)]$ plus $5 \%$ horse serum on either poly-L-lysine or poly-ornithine and laminin-coated plates or glass cover slips, respectively. Media was changed $4 \mathrm{~h}$ following plating to NB-A complete lacking serum. Half of the media volume was replaced with fresh NB-A complete every $4 \mathrm{~d}$. Cells were maintained at $37^{\circ} \mathrm{C}$ in a humidified environment of $95 \%$ air $/ 5 \% \mathrm{CO}_{2}$.

\section{Glutamate toxicity in primary neuronal cultures}

At 14 DIV coverslips with cultured neurons were secured in a flowthrough chamber fed $\mathrm{HH}$ buffer via a gravity perfusion system and mounted on an IX-71 epifluorescence microscope. For DCD and DHE experiments a baseline was established with a 2 min perfusion of $\mathrm{HH}$ buffer of the following composition: $\mathrm{NaCl}(140 \mathrm{~mm}), \mathrm{KCl}(5 \mathrm{~mm}), \mathrm{CaCl}_{2}$ (1.3 mM), $\mathrm{MgCl}_{2}(0.5 \mathrm{~mm}), \mathrm{MgSO}_{4}(0.4 \mathrm{~mm}), \mathrm{KH}_{2} \mathrm{PO}_{4}(0.4 \mathrm{~mm})$, $\mathrm{Na}_{2} \mathrm{HPO}_{4}(0.6 \mathrm{~mm}), \mathrm{NaHCO}_{3}(3 \mathrm{~mm})$, HEPES $(10 \mathrm{~mm})$, D-glucose $(10$ $\mathrm{mM}$ ), and at $310 \mathrm{mOsM}, \mathrm{pH}$ 7.4. The perfusion was then switched to a solution containing $100 \mu \mathrm{m}$ glutamate, $10 \mu \mathrm{m}$ glycine, and 200 nм TTX (Castilho et al., 1999).

\section{Oxygen-glucose deprivation of neuronal cultures}

For OGD, the medium of cortical cultures was exchanged on 14 DIV with NB-A medium without glucose (A24775, Invitrogen) that had previously been equilibrated with $94 \% \mathrm{~N}_{2}, 5 \% \mathrm{CO}_{2}$, and $1 \% \mathrm{O}_{2}$. The cultures were maintained in a Billups-Rothenberg modular incubator chamber flushed in the same gas mixture for $30 \mathrm{~min}$. After adding back the original, glucose-containing NB-A medium, cultures were returned to ambient oxygen and $5 \% \mathrm{CO}_{2}$. Control cultures were mock-treated with normoglycemic/normoxic conditions. After $24 \mathrm{~h}$, cultures were fixed in $4 \%$ paraformaldehyde and immunofluorescently labeled for MAP2B; nuclei were stained with Hoechst $33342(1 \mu \mathrm{g} / \mathrm{ml})$. Twenty epifluorescence images per culture were subjected to MAP2B densitometry and counts of nuclei using custom-written macros for ImageJ. Densitometry values and nuclei counts of OGD-treated cultures were normalized to mock-deprived cultures to determine percentage MAP2B and nuclei remaining.

\section{Fura-FF cytosolic $\mathrm{Ca}^{2+}$ imaging}

Cytosolic $\mathrm{Ca}^{2+}$ imaging was performed similarly to the protocol described by Schnizler et al. (2008). Cultures 14 DIV were incubated at $22^{\circ} \mathrm{C}$ for $30 \mathrm{~min}$ in $2 \mu \mathrm{M}$ Fura-FF/AM (Invitrogen) and $0.01 \%$ pluronic acid in $2 \mathrm{ml} \mathrm{HH}$ buffer. The coverslip was then secured in a flowthrough chamber fed $\mathrm{HH}$ buffer via a gravity perfusion system and mounted on an inverted IX-71 epifluorescence microscope (Olympus). Fura-FF fluorescence was sequentially excited at $340 \mathrm{~nm}$ and $380 \mathrm{~nm}$ via a Polychrome V monochromator (TILL Photonics) with either a $20 \times$ lens or a $40 \times$ oil-immersion objective lens (Olympus). Fluorescent emission at $510(80) \mathrm{nm}$ was collected at $0.2 \mathrm{~Hz}$ sampling frequency by a Photonics IMAGO CCD camera coupled to TillVisION live acquisition software. $\left[\mathrm{Ca}^{2+}\right]_{\mathrm{i}}$ was quantified as the background subtracted fluorescence ratio $(340 / 380 \mathrm{~nm})$ multiplied by 100 .

\section{Analysis of DCD latency}

For those neurons that produced DCD, latent period duration was measured as follows: the raw trace recording (converted to $\left[\mathrm{Ca}^{2+}\right]_{\mathrm{i}}$ as described) was smoothed using a running average protocol (SigmaPlot 13 software); the first derivative to the smoothed trace was then calculated and plotted as a function of time; the times corresponding to peak glutamate $\left[\mathrm{Ca}^{2+}\right]_{\mathrm{i}}$ response slope and peak DCD slope were determined; the duration of time in minutes between the two peaks of the slope was calculated as the latent period duration.

\section{Superoxide imaging in primary neuronal cultures}

At 14 DIV coverslips with cultured neurons were secured in a flowthrough chamber fed $\mathrm{HH}$ buffer via a gravity perfusion system and mounted on an IX-71 epifluorescence microscope (Olympus). DHE (5 $\mu \mathrm{M}$; Invitrogen) was perfused in with glutamate and DHE fluorescence was excited at $520 \mathrm{~nm}$ with emission collected at $605 \mathrm{~nm}$ with a $20 \times$ or $40 \times$ oil-immersion lens (Olympus). Rate of DHE oxidation $(\Delta F / \mathrm{min}$, where $\Delta F$ is change in DHE fluorescence intensity as a function of time) was calculated during constant perfusion of glutamate.

\section{Respirometry}

Oxygen consumption rate (OCR) was analyzed using a Seahorse Biosciences XF 96 Extracellular Flux analyzer (Agilent Technologies) essentially as described previously (Flippo et al., 2018). Briefly, primary cortical neurons were plated on 96-well Seahorse Biosciences plates coated with poly-L-lysine. At 14 DIV NB-A media was replaced with unbuffered DMEM (DMEM base medium supplemented with $10 \mathrm{~mm}$ glucose, $1 \mathrm{~mm}$ sodium pyruvate, $2 \mathrm{~mm}$ L-glutamine, $\mathrm{pH}$ 7.4) and incubated at $37^{\circ} \mathrm{C}$ for $1 \mathrm{~h}$ prior to respiration analysis. Four OCR readings were taken for each condition and inhibitors were injected in the following order; (1) basal, (2) oligomycin (2 $\mu \mathrm{M}),(3)$ FCCP $(2 \mu \mathrm{M})$, and (4) rotenone/antimycin A (10 $\mu \mathrm{M}$ each). OCR was normalized to cell number following the assay by cresyl violet staining, measuring absorbance at $540 \mathrm{~nm}$ on a Biotek plate reader, and converting according to a set of standards of known cell number.

\section{Experimental design and statistical analysis}

Number of animals, brain sections, cultures, and cells analyzed for each experiment in this study are specified in the figure legends and were justified using power analysis. Approximately equal proportions of male and female mice were used for all experiments. Data were analyzed by Student's $t$ test (two-tailed, with Welch's correction when appropriate) for single comparisons and by one-way ANOVA followed by Dunnett's multiple-comparisons test for multiple comparisons (GraphPad Prism v7 or v8 for Windows; Fig. 1-3, available at https://doi.org/10.1523/ JNEUROSCI.1926-19.2020.f1-3). Unless noted otherwise, means $\pm 95 \%$ $\mathrm{CI}$ are plotted throughout, and significance levels are abbreviated as follows: ${ }^{*} p<0.05,{ }^{* *} p<0.01,{ }^{* *} p<0.001$, and ${ }^{* * *} p<0.0001$.

\section{Results}

\section{Loss of $B \beta 2$ has no apparent adverse consequences}

We generated a global mouse knock-out of $\mathrm{B} \beta 2$ by replacing the first coding exon of the Ppp2r2b gene with lacZ and a polyadenylation sequence to terminate the transcript (Fig. 1-1A,B, available at https://doi.org/10.1523/JNEUROSCI.1926-19.2020. f1-1). Loss of B $\beta 2$ was confirmed by qPCR (Fig. 1-1C, available at https://doi.org/10.1523/JNEUROSCI.1926-19.2020.f1-1) and by Western blotting PP2A holoenzymes purified by microcystinSepharose from total forebrain (Fig. 1-1D, available at https:// doi.org/10.1523/JNEUROSCI.1926-19.2020.f1-1). Levels of the alternative promoter variant $\mathrm{B} \beta 1$, which is also brain-specific but localizes to the cytosol (Dagda et al., 2003), were unchanged in heterozygous and homozygous $\mathrm{B} \beta 2 \mathrm{KO}$ mice (Fig. 1-1D, available at https://doi.org/10.1523/JNEUROSCI.1926-19.2020. f1-1). Total levels of the four PP2A regulatory subunits belonging to the Ppp2r2 family $(\mathrm{B} \alpha / \beta / \gamma / \delta$, recognized by a pan-specific antibody) were also not detectably affected (Fig. 1-1D, 

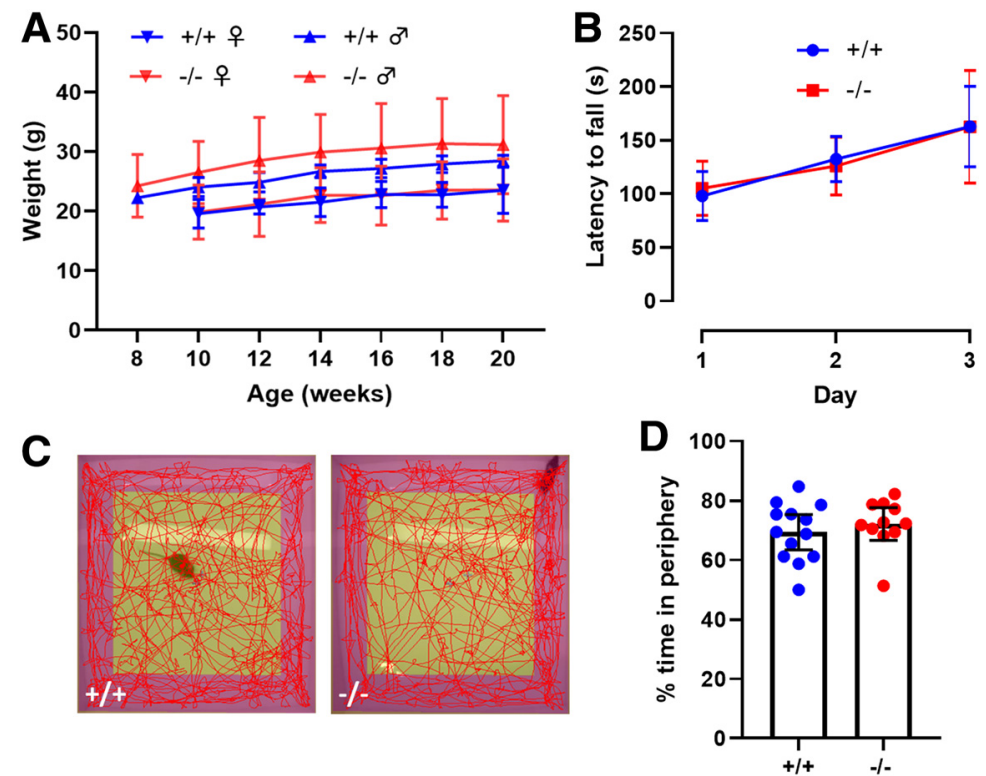

Figure 1. Phenotypic characterization of $B \beta 2 \mathrm{KO}$ mice. $A$, Weight gain on standard chow of mice of the indicated sex and genotype was monitored over $10-12$ weeks. $\boldsymbol{B}$, Motor coordination and motor learning was tested with the accelerating Rotarod test (4-40 rpm over $4 \mathrm{~min})$. C, D, Time spent in the periphery versus center of an open field was assessed as a measure of anxiety. C, Representative paths of individual mice, and (D) percentage time spent in the periphery. Tests revealed sex difference in weight, but neither sex nor genotype differences in other measures. Also unchanged by the $\mathrm{B} \beta 2 \mathrm{KO}$ were neuromuscular strength as measured by the inverted wire hang test. Also, no hindlimb clasping was observed. Plotted are means $\pm 95 \% \mathrm{Cl}$ of 4-5 mice per sex and genotype in $\boldsymbol{A}$, and $11-13$ per genotype in $\boldsymbol{B}$ and $\boldsymbol{D}$. B $\beta 2 \mathrm{KO}$ strategy and validation are shown in Figure 1-1, available at https://doi.org/10.1523/JNEUROSCI.1926-19.2020.f1-1. Additional openfield and home-cage activity data are shown in Figure 1-2, available at https://doi.org/10.1523/ JNEUROSCI.1926-19.2020.f1-2.

available at https://doi.org/10.1523/JNEUROSCI.1926-19.2020. f1-1), suggesting that the $\mathrm{B} \beta 2 \mathrm{KO}$ removes a relatively small pool of PP2A holoenzymes from the brain. $\mathrm{B} \beta 2 \mathrm{KO}$ mice are born in Mendelian ratios, live a typical life span, and gain weight at the same rate as their WT littermates (Fig. 1A). Motor-coordination and motor-learning as assessed by the Rotarod test were likewise unaffected by deletion of the PP2A subunit (Fig. 1B). Anxiety levels as inferred from preference of the periphery in the open-field test was normal (Fig. $1 C, D$ ), as were activity measures, including distance traveled (Fig. 1-2A, available at https://doi.org/10.1523/JNEUROSCI.1926-19.2020. f1-2), velocity (Fig. 1-2B, available at https://doi.org/10.1523/ JNEUROSCI.1926-19.2020.f1-2), and number of rearings in the open field (Fig. 1-2C, available at https://doi.org/10.1523/ JNEUROSCI.1926-19.2020.f1-2). Diurnal activity levels were recorded over $23 \mathrm{~h}$ with a home cage monitoring system. Again, the $\mathrm{B} \beta 2 \mathrm{KO}$ did not impact day/night variations and cumulative measures of distance traveled (Fig. 1-2D, available at https://doi.org/10.1523/JNEUROSCI.1926-19.2020.f1-2), mobility (Fig. 1-2E, available at https://doi.org/10.1523/JNEUROSCI.192619.2020.f1-2), and time spent near the food hopper (Fig. 1-2E, available at https://doi.org/10.1523/JNEUROSCI.1926-19.2020.f1-2).

\section{B $\beta 2 \mathrm{KO}$ decreases infarct volume following MCAO and} increases mitochondrial profile area in neurons

To evaluate whether deletion of $\mathrm{B} \beta 2$ influences cerebral ischemic sensitivity in vivo mice were subjected to transient ( $45 \mathrm{~min}$ ) MCAO, which resulted in similar levels of blood flow reduction in $\mathrm{B} \beta 2 \mathrm{KO}$ and WT mice (Fig. 2-1, available at https://doi.org/ 10.1523/JNEUROSCI.1926-19.2020.f2-1). Indicative of improved cell survival, cerebral infarct volume was decreased by $40-60 \%$ in mice lacking one or both $\mathrm{B} \beta 2$ alleles (Fig. 2A,B). Examining mitochondrial ultrastructure revealed that heterozygous and homozygous $\mathrm{B} \beta 2$ deletion increased mitochondrial profile area in neurons of the hippocampus and cortex (Fig. 2C,D), but not of hippocampal astrocytes or neurons in the amygdala and striatum (Fig. 2-2A, available at https://doi.org/ 10.1523/JNEUROSCI.1926-19.2020.f2-2). No genotype differences in mitochondrial content were observed, consistent with a selective effect of $\mathrm{B} \beta 2$ deletion on the mitochondrial fission/fusion equilibrium as opposed to total mitochondrial mass (Fig. 2-2B,D, available at https://doi.org/10.1523/JNEUROSCI.1926-19.2020.f22). Additionally, we observed no changes in total protein expression of Drp1 or the mitochondrial fusion enzyme Opal (Fig. 2-3, available at https://doi.org/ 10.1523/JNEUROSCI.1926-19.2020.f2-3) indicating that altered mitochondrial morphology was not due to changes in expression of mitochondrial fission/and fusion genes.

\section{Deletion of $\mathrm{B} \beta 2$ reduces $\mathrm{PP} 2 \mathrm{~A}$ association with mitochondria and promotes phosphorylation of Drp1 at $\mathbf{S 6 3 7}$}

Given we observed no changes in total protein expression of mitochondrial fission/fusion enzymes to determine if changes in the mitochondrial fission/fusion equilibrium observed in mice lacking $\mathrm{B} \beta 2$ were related to Drp1-S637 phosphorylation and localization of PP2A to mitochondria we assessed levels of each in mitochondrial fractions isolated from the forebrain of $\mathrm{B} \beta 2^{-1-}$ and WT mice. In agreement with the observed increase in mitochondrial profile area, suggestive of inhibited mitochondrial fission, PP2A catalytic subunit levels were decreased, whereas Drp1-S637 phosphorylation was increased in mitochondrial fractions from $\mathrm{B} \beta 2^{-1-}$ forebrains (Fig. 3). In total forebrain homogenates, in contrast, Drp1 levels and phosphorylation were unaffected (Fig. 2-3, available at https://doi.org/10.1523/JNEUROSCI.1926-19.2020.f2-3), consistent with the notion that the majority of Drp1 is cytosolic and that $\mathrm{PP} 2 \mathrm{~A} / \mathrm{B} \beta 2$ selectively regulates the mitochondria-associated pool of Drp1.

\section{Deletion of $\mathrm{B} \beta 2$ delays calcium overload and blunts} superoxide generation induced by OGD in the hippocampal CA1 region

Loss of $\mathrm{Ca}^{2+}$ homeostasis in neurons during ischemic insult, known as DCD, contributes to neuronal death during cerebral ischemia. To determine if deletion of $\mathrm{B} \beta 2$ improves the ability of neurons to maintain $\mathrm{Ca}^{2+}$ homeostasis during an ischemic insult, we expressed the fluorescent $\mathrm{Ca}^{2+}$ reporter GCAMP6f by stereotaxic delivery of virus into the hippocampus of WT and $\mathrm{B} \beta 2 \mathrm{KO}$ mice. To model the environment of the ischemic core, intracellular $\mathrm{Ca}^{2+}$ levels in response to OGD were measured by two-photon imaging of the CA1 region of acutely prepared hippocampal slices (Fig. $4 A$ ). In agreement with the in vivo cerebral ischemia results, deletion of $\mathrm{B} \beta 2$ prolonged the latency to $\mathrm{DCD}$ in $\mathrm{CA} 1$ neurons as measured as the time until the steepest rise in GCaMP6 fluorescence (Fig. 4B,C).

Mitochondrial reactive oxygen species, in particular superoxide play a prominent role in ischemic neuronal death, and bursts of superoxide generation may trigger DCD (Vesce et al., 2004). 
To monitor superoxide production, acute hippocampal slices were preloaded and then continuously superfused with DHE, a cell-permeable dye that fluoresces and intercalates into DNA on oxidation by superoxide. The $\mathrm{B} \beta 2 \mathrm{KO}$ slowed basal superoxide production from $6.6 \pm 1.6$ to $4.6 \pm 0.6 \Delta \mathrm{Fl} / \mathrm{min}$, resulting in lower baseline DHE fluorescence when two-photon imaging of the CA1 region commenced (Fig. 4D,E). Moreover, the $\mathrm{KO}$ all but eliminated the rapid rise in superoxide production that OGD triggered in hippocampal slices from WT mice (Fig. 4E,F).

\section{Deletion of B $\beta 2$ and Drp1 S637 phosphorylation delays calcium overload and inhibits superoxide production induced by glutamate excitotoxic challenge in primary hippocampal neurons} Although the results above indicated that genetic removal of $\mathrm{B} \beta 2$ can delay DCD and blunt toxic superoxide accumulation, it was unclear whether these effects were cell autonomous and whether they may also occur in areas adjacent to the ischemic core. During cerebral stroke, neurons in the ischemic core release excitotoxic levels of glutamate, which kills neurons in the surrounding ischemic penumbra via mitochondrial $\mathrm{Ca}^{2+}$ overload and/or DCD (Nicholls and Budd, 1998; Ramos-Cabrer et al., 2011). To determine whether the effects of $\mathrm{B} \beta 2$ deletion and additionally Drp1 S637 phosphorylation were cell autonomous in response to glutamate excitotoxicity we turned to using primary hippocampal neuron cultures from WT and $\mathrm{B} \beta 2 \mathrm{KO}$ mice. When challenged with $100 \mu \mathrm{M}$ glutamate, cultured hippocampal $\mathrm{B} \beta 2^{-1-}$ neurons exhibited an increased latency to DCD compared with WT neurons (Fig. 5A-C), which was of similar magnitude as in hippocampal slices deprived of oxygen and glucose (compare Fig. 4B,C). Implicating increased Drp1-S637 phosphorylation in this neuroprotective effect, lentiviral replacement of endogenous with phosphomimetic Drp1 (GFP-Drp1 S637D; Flippo et al., 2018) in WT hippocampal neurons mimicked the effects of $\mathrm{B} \beta 2$ deletion (Fig. 5D-F). Consistent with DHE imaging in oxygen and glucose-deprived hippocampal slices, we found that $\mathrm{B} \beta 2^{-/-}$neurons displayed lower rates of superoxide production under glutamate perfusion (Fig. $6 A-C$ ). Similar to the DCD experiments, phosphomimetic Drp1 substitution in WT neurons again mimicked, and perhaps even surpassed the detoxifying effects of deleting $\mathrm{B} \beta 2$ (Fig. $6 D-F$ ).

\section{$B \beta 2$ deletion improves spare respiratory capacity and neuronal survival after ischemia}

$\mathrm{Ca}^{2+}$ homeostasis fails when ischemia compromises mitochondrial ATP production (Nicholls et al., 2007; Yadava and Nicholls, 2007). Measuring oxygen consumption of cultured neurons subjected to mitochondrial stress tests, we found that spare respiratory capacity was increased both by deletion of the Drp1 phosphatase $\mathrm{B} \beta 2$ (Fig. 7A) and by phosphomimetic replacement of Drp1 (Fig. $7 B$ ). Further, deletion of $\mathrm{B} \beta 2$ protected against death of cultured neurons challenged by OGD, as measured by a decrease in neuronal MAP2B staining (Fig. $7 C, D$ ) and loss of nuclei (Fig. $7 E$ ). These results indicate that $\mathrm{B} \beta 2$ regulates ischemic sensitivity in a neuron-autonomous fashion. We recently reported that deletion of AKAP1, which recruits protein kinase
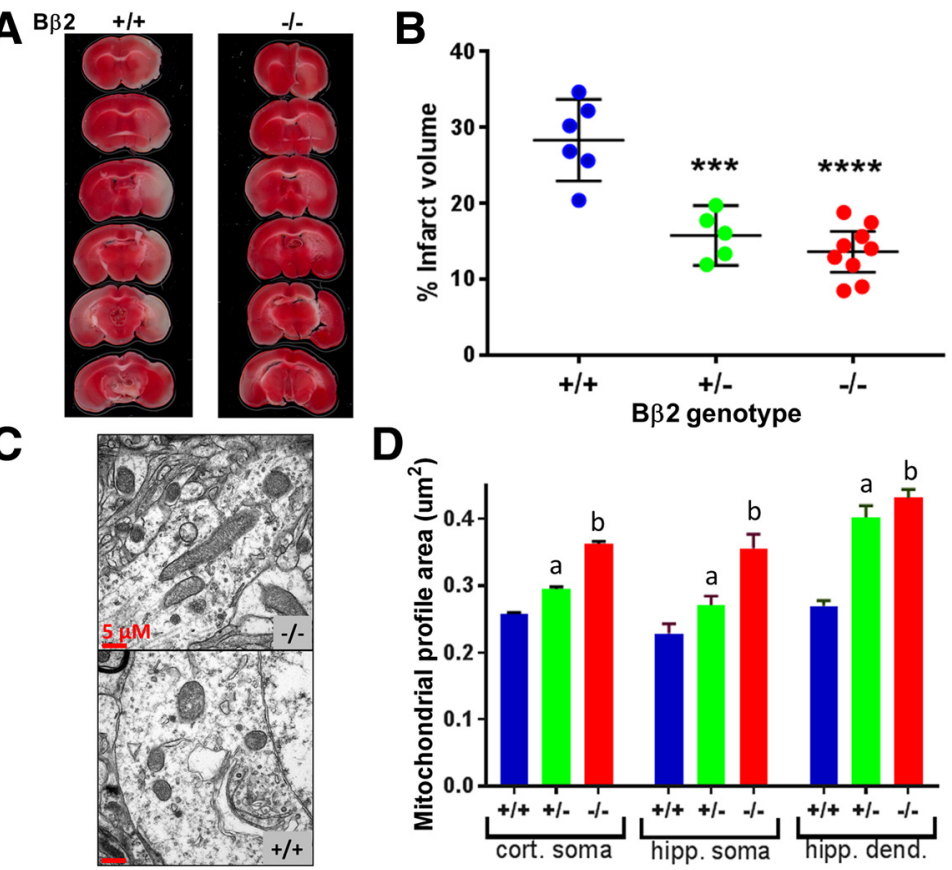

Figure 2. $\mathrm{B} \beta 2 \mathrm{KO}$ decreases infarct volume following MCAO and increases mitochondrial profile area in neurons. $\boldsymbol{A}$, Triphenyltetrazolium chloride staining of sliced brains of WT $(+/+)$ and $\mathrm{B} \beta 2 \mathrm{KO}(-/-)$ mice following 45 min MCA0; red represents living tissue, whereas white defines the infarcted area. $\boldsymbol{B}$, Infarc TEM images of (Fig. 2-1, available at https://doi.org/10.1523/JNEUROSCl.1926-19.2020.f2-1), other mitochondrial parameters 2-2, available at https://doi.org/10.1523/JNEUROSCI.1926-19.2020.f2-2), and expression of mitochondrial fission/fusion proteins (Fig. 2-3, available at https://doi.org/10.1523/JNEUROSCl.1926-19.2020.f2-3).

A to mitochondria, exacerbates ischemic brain damage via loss of inhibitory Drp1 phosphorylation at Ser637 (Flippo et al., 2018). We crossed mice lacking $\mathrm{B} \beta 2$ with mice lacking AKAP1 and found that deletion of the Drp1 phosphatase normalized Drp1 S637 phosphorylation levels to WT levels (Fig. 7E). Coincident with restoration of inhibitory Drp1 phosphorylation, deletion of $\mathrm{B} \beta 2$ in mice lacking AKAP1 completely rescued the worsened stroke outcome associated with AKAP1 deletion (Fig. $7 F$ ), implicating Drp1 S637 as the common effector regulating ischemic sensitivity in vivo.

\section{Discussion}

Here, we identified a role for the neuronal and mitochondria-targeted $\mathrm{PP} 2 \mathrm{~A} / \mathrm{B} \beta 2$ holoenzyme in opposition to the neuroprotective AKAP1/PKA complex, acting on an evolutionary conserved inhibitory phosphorylation site on Drp1. Previous preclinical studies suggested that pharmacological Drp1 inhibition could have therapeutic benefit limiting brain damage after ischemic stroke (Grohm et al., 2012; Zhao et al., 2014; Li et al., 2015). However, the specificity and efficacy of the Drp1 inhibitor mdivi-1 has been challenged (Bordt et al., 2017). Importantly, our work here maintains a critical role for Drp1-mediated mitochondrial fission in dictating sensitivity to ischemic injury and suggests that phosphorylation of Drp1 at S637 functions as an important moderator of stroke outcomes.

Drp1 is also phosphorylated at S616, and cyclin-dependent kinases, extracellular signal-regulated kinases, and protein 
A

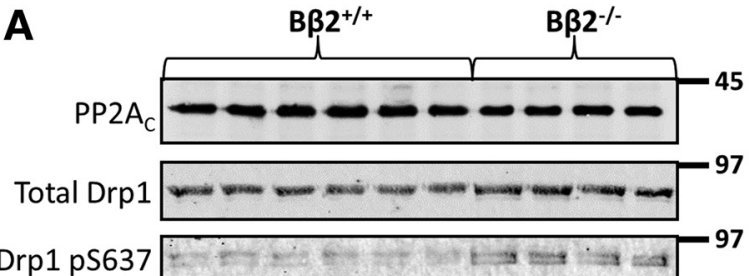

Drp1 pS637

Poncs

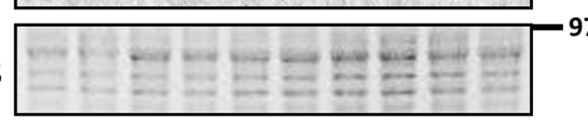

C

Total Drp1

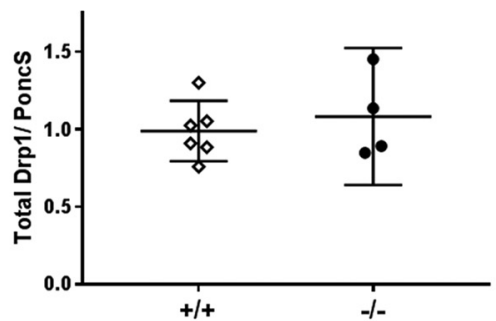

B

PP2A catalytic subunit

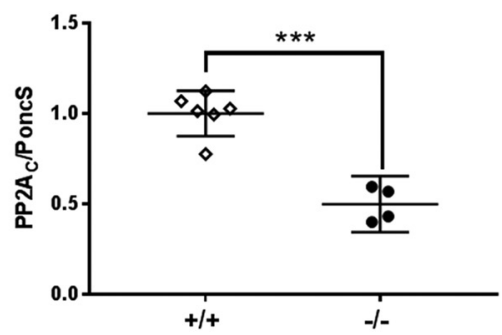

D Drp1-S637 phosphorylation

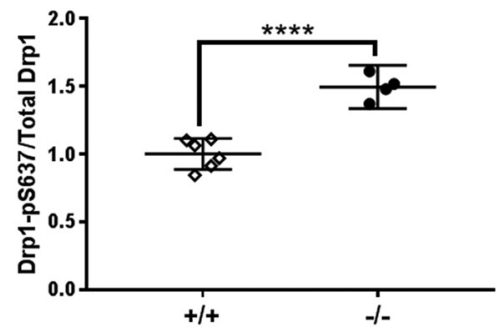

Figure 3. Deletion of $B \beta 2$ reduces PP2A association with mitochondria and promotes phosphorylation of Drp1 at S637. A, Immunoblots for the PP2A catalytic subunit (PP2A $)$, total Drp1, and phosphorylated Drp1-S637 of mitochondrial fractions from $B \beta 2 \mathrm{WT}(+/+)$ and $\mathrm{B} \beta 2 \mathrm{KO}(-/-)$ forebrains. $\boldsymbol{B}-\boldsymbol{D}$, Densitometric quantification of immunoblot signals relative to total protein (Ponceau S, PoncS; $\boldsymbol{B}, \boldsymbol{C}$ ) or total Drp1 (D). Shown are mean $\pm 95 \% \mathrm{Cl}$ of six WT and four B $\beta 2$ KO mice. ${ }^{* * *} p<0.001,{ }^{* * * *} p<0.0001$ by unpaired, two-tailed $t$ test.
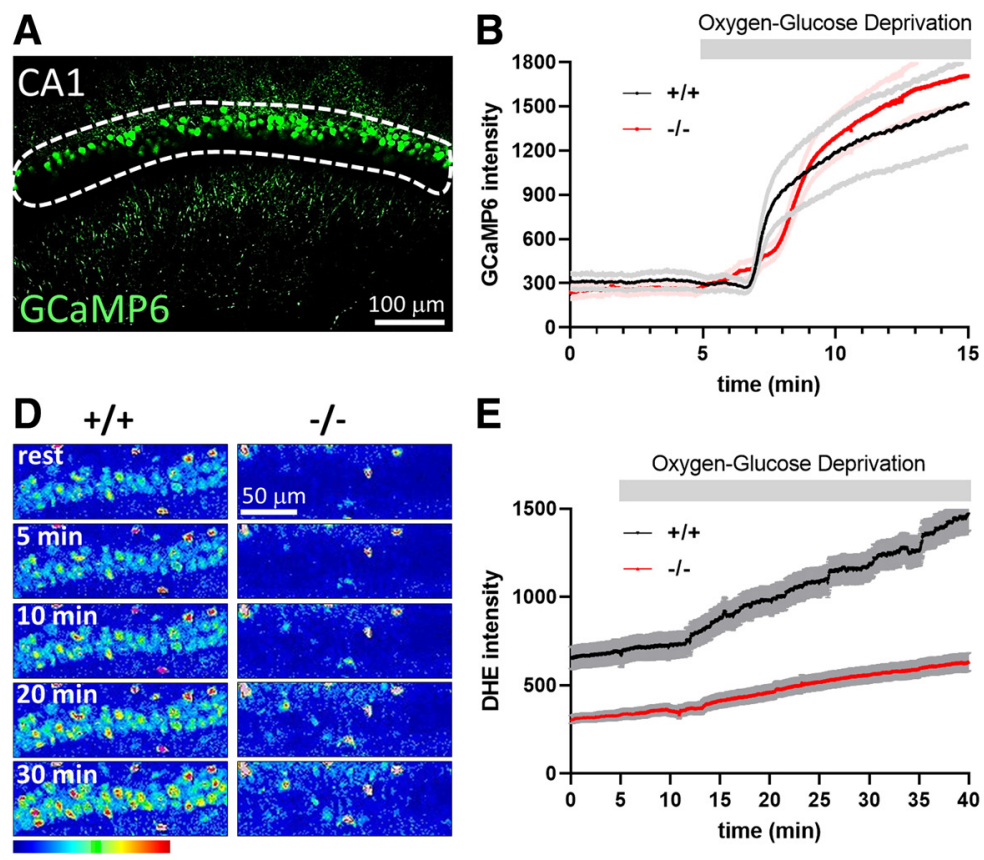

$-/-$

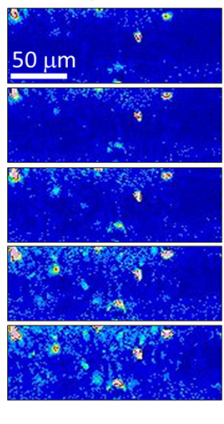

E

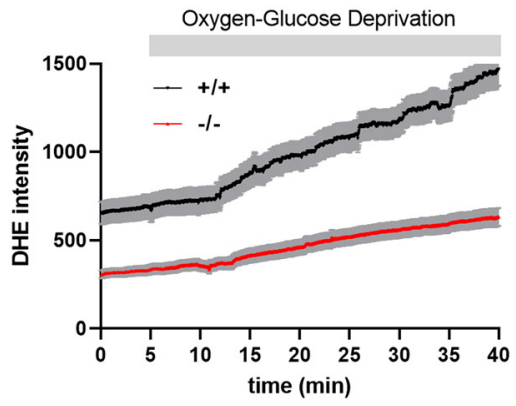

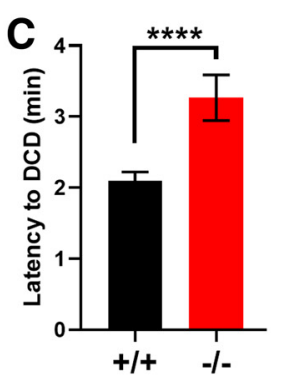

$\mathbf{F}$

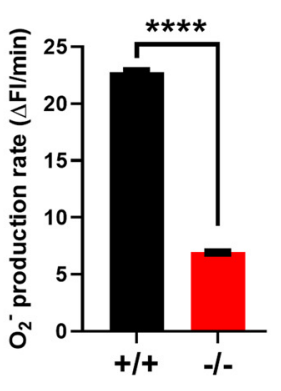

Figure 4. Deletion of $B \beta 2$ delays calcium dysregulation and slows superoxide production in the CA1 region of the hippocampus during $0 G D$. $A$, Representative two-photon microscopy image of GCaMP6 expression in the CA1 region of an acute hippocampal slice. $\boldsymbol{B}$, Average traces of GCaMP6 fluorescence intensity before and during 0GD (gray bar). $\boldsymbol{C}$, The latency to DCD was determined as the time from the onset of OGD to the peak of the first derivative (rate) of fluorescence intensity for each genotype. $\boldsymbol{D}$, Representative two-photon images of DHE fluorescence (pseudocolored according to the scale at the bottom; blue, lowest; red, highest) at rest and at the indicated times of OGD in the CA1 hippocampus. $E$, Average traces of DHE fluorescence intensity before and during $\mathrm{OGD}$ (gray bar). $\boldsymbol{F}$, Superoxide $\left(\mathrm{O}_{2}{ }^{-}\right)$production rates were determined from linear fits of the DHE fluorescence traces during $0 \mathrm{GD}$. Mean $\pm 95 \% \mathrm{CI}(\boldsymbol{B}$, gray and pink lines; $\boldsymbol{E}$, gray areas) are plotted from 106 and 159 cells from three and four slices from $3 \mathrm{~B} \beta 2^{+/+}$mice and $3 \mathrm{~B} \beta 2^{-/-}$mice, respectively, in $\boldsymbol{B}$ and $\boldsymbol{C}$, and from 118 and 147 cells from four slices each from $3 \mathrm{~B} \beta 2^{+/+}$mice and $3 \mathrm{~B} \beta 2^{-1-}$ mice, respectively, in $\boldsymbol{E}$ and $\boldsymbol{F}$. ${ }^{* * * *} p<0.0001$ by Welch's two-tailed $t$ test.

kinase C have been implicated as S616 kinases. However, in contrast to S637, phosphorylation at S616 was reported to activate Drp1, promoting mitochondrial fission (Taguchi et al., 2007; Qi et al., 2011; Strack et al., 2013; Kashatus et al., 2015). We detected no change in Drp1 S616 phosphorylation levels in total lysates or mitochondrial fractions from $\mathrm{B} \beta 2 \mathrm{KO}$ brains (data not shown).
This suggests that either PP2A/B $\beta 2$ does not dephosphorylate $\mathrm{S} 616$, or that kinases dominate over phosphatases at this site. High basal stoichiometry of Drp1 S616 phosphorylation ( 40\%; Strack et al., 2013) argues for the latter explanation.

Ischemia and excitotoxicity trigger rapid mitochondrial fragmentation; however, this is thought to be independent of Drp1 

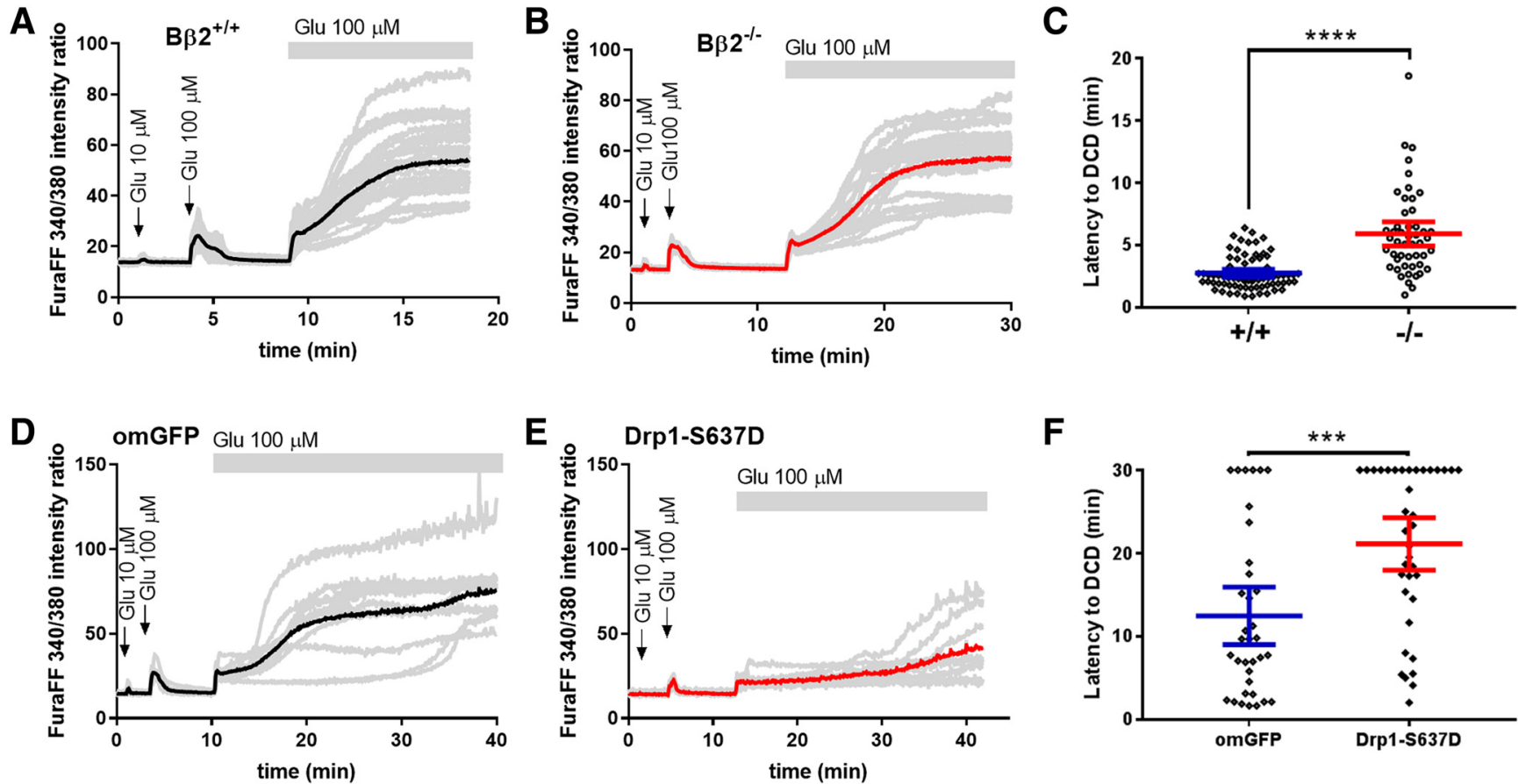

Figure 5. Deletion of $B \beta 2$ and Drp1 $S 637$ phosphorylation delays calcium overload induced by glutamate excitotoxic challenge. $A, B$, Individual (gray) and average (black, red) traces of cytosolic $\left[\mathrm{Ca}^{2+}\right]$ in hippocampal neurons cultured from $\mathrm{B} \beta 2^{+/+}$and $\mathrm{B} \beta 2^{-1-}$ mice in response to $30 \mathrm{~s}$ pulses of 10 and $100 \mu \mathrm{m}$ glutamate (arrows) and to sustained perfusion with $100 \mu \mathrm{m}$ glutamate. Plotted are 340/380 excitation ratios times 100. C, Latency to DCD was calculated from traces in $\boldsymbol{A}$ and $\boldsymbol{B}$ as the time between the peaks of the first derivative (or rate) of the first and second $\left[\mathrm{Ca}^{2+}\right]_{\mathrm{r}}$ rise following chronic glutamate treatment. $\mathbf{D}, \boldsymbol{E}$, Individual (gray) and average (black, red) traces of cytosolic $\left[\mathrm{Ca}^{2+}\right]$ in response to $30 \mathrm{~s}$ pulses of 10 and $100 \mu \mathrm{m}$ glutamate (arrows) and to sustained perfusion with $100 \mu \mathrm{m}$ glutamate in WT hippocampal neurons following lentiviral transduction of either outer-mitochondrial (om)GFP or shRNA-mediated replacement of endogenous Drp1 with constitutively phosphorylated GFP-Drp1 (S637D). F, DCD latency in response to $100 \mu \mathrm{m}$ glutamate was determined as in C. Note that 6 of 34 omGFP expressing neurons (18\%), but 15 of 37 Drp1-S637D expressing neurons (41\%) did not undergo DCD during the recording period. Data points and traces represent individual neurons cultured from three to four mice/condition with mean $\pm 95 \%$ Cl plotted throughout. ${ }^{* * *} p<0.001,{ }^{* * *} p<0.0001$ by Welch's $(\boldsymbol{C})$ and unpaired, two-tailed $t$ tests $(\boldsymbol{F})$.

A

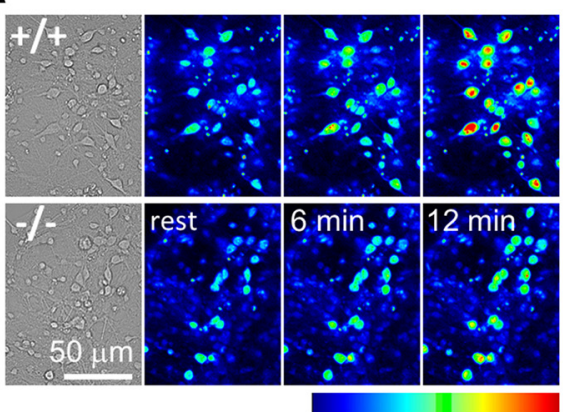

D
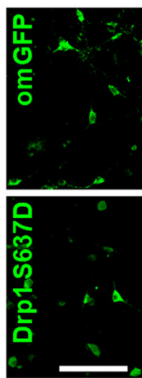
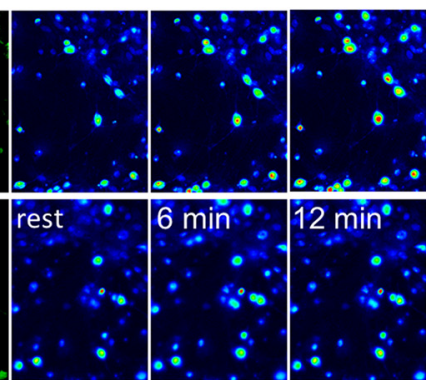

B

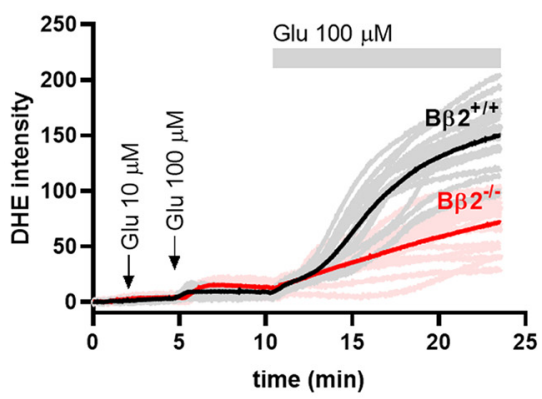

E

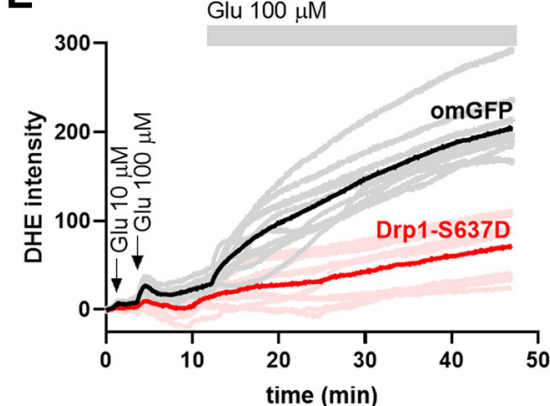

C

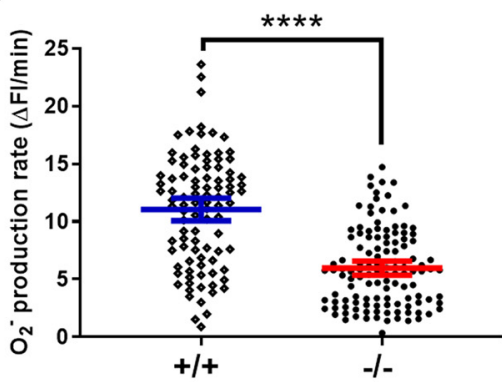

F

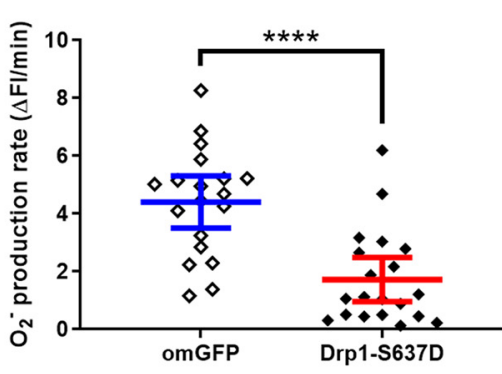

Figure 6. Deletion of $\mathrm{B} \beta 2$ and Drp1 5637 phosphorylation inhibits superoxide production under excitotoxic glutamate challenge. $\boldsymbol{A}$, Representative images show color-coded fluorescence intensity of the superoxide indicator DHE in hippocampal neurons (14 DIV) cultured from WT $(+/+)$ and B $\beta 2 \mathrm{KO}(-/-)$ mice at rest and at the indicated times after the start of $100 \mu \mathrm{m}$ glutamate superfusion. The color lookup table scale is shown at the bottom. $\boldsymbol{B}$, DHE fluorescence intensity traces (individual, gray; average, black or red) in response to $30 \mathrm{~s}$ (arrows) or constant (bar) glutamate superfusion in $\mathrm{B} \beta 2^{+/+}$and $\mathrm{B} \beta 2^{-1-}$ hippocampal neurons. $\boldsymbol{C}$, Summary plots of superoxide production rates after glutamate treatment. $\boldsymbol{D}-\boldsymbol{F}$, superoxide production assays as described for $\boldsymbol{A}-\boldsymbol{C}$, but involving WT hippocampal cultures infected with lentivirus expressing omGFP or GFP-Drp1 S637D. Shown are representative images $(\boldsymbol{D})$, traces $(\boldsymbol{E})$, and rate quantification $(\boldsymbol{F})$. Data points and traces represent individual neurons cultured from 3 to 4 mice/condition with mean $\pm 95 \%$ Cl plotted throughout. ${ }^{* * * *} p<0.0001$ by Welch's $(\boldsymbol{C})$ and unpaired, two-tailed $t$ tests $(\boldsymbol{F})$. 
A

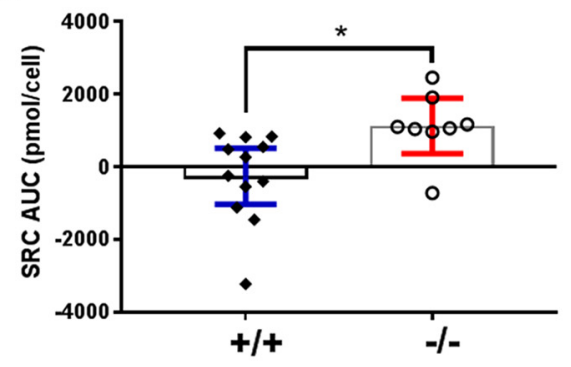

B

C

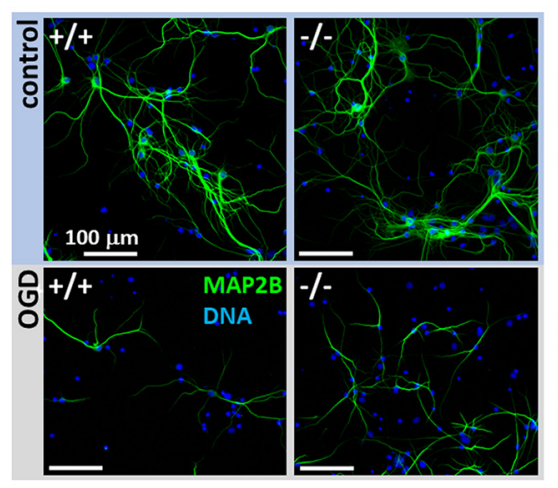

$\mathbf{F}$

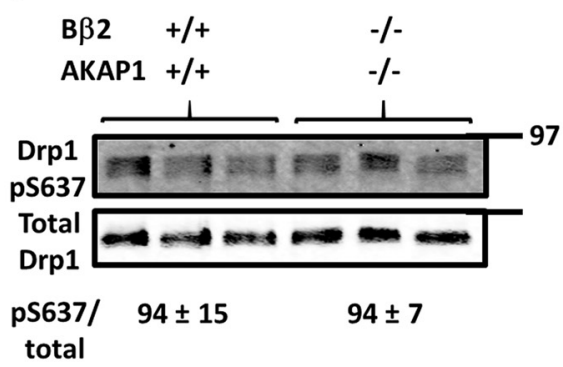

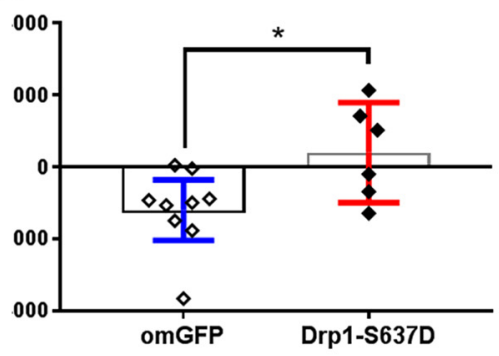

D
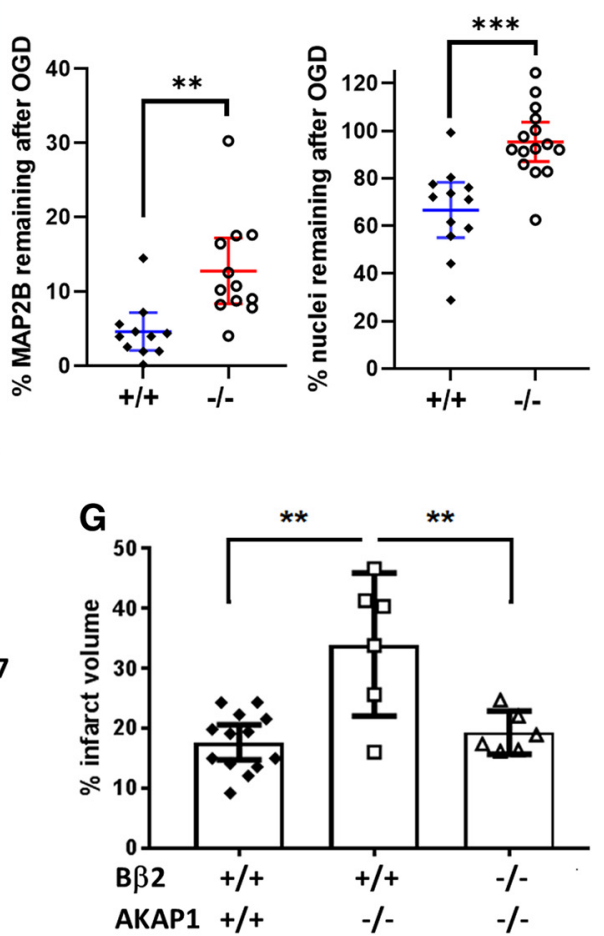

Figure 7. $B \beta 2$ deletion improves spare respiratory capacity and neuronal survival after ischemia. $A$, Spare respiratory capacity (SRC) determined as the area-under-the curve (AUC) of uncoupled respiration minus basal respiration measured in cortical neurons cultured from WT $(+/+)$ and $B \beta 2 \mathrm{KO}(-/-)$ mice. $\boldsymbol{B}$, Spare respiratory capacity of cortical neurons expressing omGFP or constitutively phosphorylated GFP-Drp1 (S637D). C, D, Survival of cortical cultures from $+/+$ and $-/-$ mice subjected to 45 min of $O G D$ was assessed $24 \mathrm{~h}$ later by immunofluorescence labeling of MAP2B, a protein that is rapidly degraded in challenged neurons ( $\boldsymbol{C}$, representative images; $\boldsymbol{D}$, densitometry), and by automated counts of nuclei stained by Hoechst 33342 ( $\boldsymbol{E}$, densitometry and counts normalized to normoxic conditions). $\boldsymbol{F}$, Forebrain mitochondrial fractions from three mice either WT for or lacking AKAP1 and $B \beta 2$ were assayed for Drp1 phosphorylation by immunoblotting. $G$, Mice of the indicated genotypes were subjected to 30 min MCAO and infarct volumes were determined after $24 \mathrm{~h}$ by TTC staining as in Figure $2, \boldsymbol{A}$ and $\boldsymbol{B}$. Data for WT and AKAP1 K0 mice were previously reported (Flippo et al., 2018) and are shown here for comparison to double $\mathrm{KO}$ mice. For $\boldsymbol{A}, \boldsymbol{B}$, and $\boldsymbol{G}$ data points represent mice, with $n=12$ for $B \beta 2^{+/+}, 8$ for $\mathrm{B} \beta 2^{-1-}, 9$ for omGFP, 6 for Drp1-S637D, 13 for AKAP1 ${ }^{+/+} / \mathrm{B} \beta 2^{+/+}$, and 6 each for AKAP1 $1^{-1 /} / \mathrm{B} \beta 2^{+/+}$and AKAP1 $1^{-/-} / \mathrm{B} \beta 2^{-1-}$. D, $\boldsymbol{E}$, Data points represent individual cultures from four WT and five $\mathrm{B} \beta 2^{-/-}$mice. Mean $\pm 95 \% \mathrm{Cl}$ are plotted throughout. ${ }^{*} p<0.05,{ }^{* *} p<0.01$, ${ }^{* *} p<0.005$, for $7 \mathrm{~A}-\mathrm{E}-/$ - was compared with $+/+$ using unpaired, twotailed $t$ tests and in $\mathbf{G}$ one-way ANOVA was used for comparison between genotypes. Quantitation of electron transport chain complexes is shown in Figure 7-1, available at https://doi.org/10.1523/JNEUROSCI.1926-19.2020.f7-1.

and instead caused by osmotic swelling of mitochondria (Barsoum et al., 2006; Shalbuyeva et al., 2006; Brustovetsky et al., 2009; Young et al., 2010; Slupe et al., 2013). In this context, $\mathrm{PP} 2 \mathrm{~A} / \mathrm{B} \beta 2$ and the opposing AKAP1/PKA likely influence stroke outcomes not by promoting and inhibiting mitochondrial fragmentation during the ischemic onslaught, but by shaping the mitochondrial network prior to the insult, thereby determining the likelihood that neurons survive in the ischemic penumbra. Indeed, the AKAP1 KO reduces (Flippo et al., 2018), whereas the $\mathrm{B} \beta 2 \mathrm{KO}$ increases mitochondrial spare respiratory capacity (Fig. 7A), an indicator of resilience to metabolic stress (Nicholls et al., 2007; Yadava and Nicholls, 2007). The mechanistic relationship underlying mitochondrial elongation and improved metabolic capacity deserves further study.

Although we did not attempt to quantify whether $\mathrm{B} \beta 2$ deletion rescues some brain regions within the territory of the middle cerebral artery better than others from stroke, such regional selectivity would indeed be predicted. Indeed, according to electron microscopy, the $\mathrm{B} \beta 2 \mathrm{KO}$ leads to mitochondrial elongation in the cortex and hippocampus (Fig. $2 D$ ), but not in the striatum and amygdala (Fig. 2-2A, available at https://doi.org/10.1523/JNEUROSCI.192619.2020.f2-2). Higher $\mathrm{B} \beta 2$ expression in the former compared with the latter regions is one possible explanation. Additionally, available single-cell RNA sequencing data http://mousebrain.org/) suggest that Drp1 itself is more highly expressed in the cortex and hippocampus than the striatum, which may increase the effect magnitude of the $\mathrm{B} \beta 2 \mathrm{KO}$ on mitochondrial shape in the cortex and hippocampus relative to the striatum.

Although we generated a global $\mathrm{KO}$ of $\mathrm{B} \beta 2$, we did not detect any adverse behavioral or physiological consequences in the homozygous KO. This may in part be rationalized by nervous system-specific expression of the $\mathrm{B} \beta$ gene (Dagda et al., 2003; one of 12 $\mathrm{PP} 2 \mathrm{~A}$ regulatory subunit genes) and maintained expression of the more abundant $\mathrm{B} \beta 1$ splice variant in the $\mathrm{B} \beta 2 \mathrm{KO}$ brain (Fig. $1-1 B$, available at https://doi.org/10.1523/ JNEUROSCI.1926-19.2020.f1-1). Still, we observed robust mitochondrial elongation in neurons and reduction of focal stroke damage even in heterozygous $\mathrm{B} \beta 2$ $\mathrm{KO}$ mice. Heterozygous effects are significant, in that they suggest that even partial reduction of $\mathrm{PP} 2 \mathrm{~A} / \mathrm{B} \beta 2$ activity may be therapeutically relevant. However, our results also raise questions regarding the physiological function of this outer-mitochondrial PP2A holoenzyme. We previously reported that mitochondrial shape, $\mathrm{PP} 2 \mathrm{~A} / \mathrm{B} \beta 2$, and AKAP1/PKA influence neurite outgrowth and synapse formation in vitro (Dickey and Strack, 2011). It will be important to assess if and how the $\mathrm{B} \beta 2 \mathrm{KO}$ impacts brain development in vivo and to challenge mice with additional behavioral, including cognitive tasks.

We found that displacing PP2A from mitochondria by deletion of its targeting subunit $\mathrm{B} \beta 2$ or by mimicking Drp1 S637 phosphorylation improves bioenergetic capacity of mitochondria 
to maintain $\mathrm{Ca}^{2+}$ homeostasis when hippocampal neurons are challenged by either OGD or glutamate excitotoxicity. Particularly striking was the robust inhibition of superoxide production that we observed in hippocampal neurons lacking $\mathrm{B} \beta 2$ ex vivo and in vitro. Superoxide toxicity is well established not only in acute ischemic neuronal injury, but also during the reperfusion phase, when mitochondrial ATP production resumes (Traystman et al., 1991; Chouchani et al., 2016). Our ex vivo and in vitro studies have only examined acute injury responses, so it is possible that $\mathrm{B} \beta 2$ influences later stages of stroke damage as well. It will be instructive to examine whether $\mathrm{B} \beta 2$ deletion (and other means of Drp1 inhibition) also blunts the superoxide surge during reperfusion, because this would extend the therapeutic window of targeting mitochondrial fission.

Although overall mitochondrial mass is unaffected (Fig. 2-2, available at https://doi.org/10.1523/JNEUROSCI.1926-19.2020. f2-2), we did detect increased expression of electron transport chain complex subunits in forebrain lysates of $\mathrm{B} \beta 2^{-1-}$ mice (Fig. 7-1, available at https://doi.org/10.1523/JNEUROSCI.192619.2020.f7-1), providing a possible explanation for increased spare respiratory capacity in $\mathrm{B} \beta 2 \mathrm{KO}$ neurons. Increased ETC complex expression and electron flux may also boost the antioxidant defense system, for instance in the form of homeostatic increases in superoxide scavengers and detoxifying enzymes that could occur in $\mathrm{B} \beta 2 \mathrm{KO}$ neurons. Although further work is required to establish the precise mechanism by which mitochondrial shape impacts bioenergetic capacity and the ability to limit superoxide toxicity during an ischemic insult, our work establishes the Drp1 S637 phosphorylation state as a pivotal regulator of neuronal susceptibility to ischemic stroke.

\section{References}

Barsoum MJ, Yuan H, Gerencser AA, Liot G, Kushnareva Y, Gräber S, Kovacs I, Lee WD, Waggoner J, Cui J, White AD, Bossy B, Martinou JC, Youle RJ, Lipton SA, Ellisman MH, Perkins GA, Bossy-Wetzel E (2006) Nitric oxide-induced mitochondrial fission is regulated by dynaminrelated GTPases in neurons. EMBO J 25:3900-3911.

Bordt EA, Clerc P, Roelofs BA, Saladino AJ, Tretter L, Adam-Vizi V, Cherok E, Khalil A, Yadava N, Ge SX, Francis TC, Kennedy NW, Picton LK, Kumar T, Uppuluri S, Miller AM, Itoh K, Karbowski M, Sesaki H, Hill RB, Polster BM (2017) The putative Drp1 inhibitor mdivi-1 is a reversible mitochondrial complex i inhibitor that modulates reactive oxygen species. Dev Cell 40:583-594.e586.

Brustovetsky T, Li V, Brustovetsky N (2009) Stimulation of glutamate receptors in cultured hippocampal neurons causes $\mathrm{Ca} 2+$-dependent mitochondrial contraction. Cell Calcium 46:18-29.

Castilho RF, Ward MW, Nicholls DG (1999) Oxidative stress, mitochondrial function, and acute glutamate excitotoxicity in cultured cerebellar granule cells. J Neurochem 72:1394-1401.

Cheng HT, Chang H, Lue HJ, Wen CY (1996) Unpredictability of triphenyltetrazolium chloride in staining irreversible ischaemia-reperfusion injury in the skeletal muscle of rats. Eur. J Surg 162:407-412.

Chouchani ET, Pell VR, James AM, Work LM, Saeb-Parsy K, Frezza C, Krieg T, Murphy MP (2016) A unifying mechanism for mitochondrial superoxide production during ischemia-reperfusion injury. Cell Metab 23:254263.

Dagda RK, Barwacz CA, Cribbs JT, Strack S (2005) Unfolding-resistant translocase targeting: a novel mechanism for outer mitochondrial membrane localization exemplified by the Bbeta2 regulatory subunit of protein phosphatase 2A. J Biol Chem 280:27375-27382.

Dagda RK, Merrill RA, Cribbs JT, Chen Y, Hell JW, Usachev YM, Strack $S$ (2008) The spinocerebellar ataxia 12 gene product and protein phosphatase $2 \mathrm{~A}$ regulatory subunit $\mathrm{B} \beta 2$ antagonizes neuronal survival by promoting mitochondrial fission. J Biol Chem 283:36241-36248

Dagda RK, Zaucha JA, Wadzinski BE, Strack S (2003) A developmentally regulated, neuron-specific splice variant of the variable subunit $\mathrm{B} \beta$ targets protein phosphatase $2 \mathrm{~A}$ to mitochondria and modulates apoptosis. J Biol Chem 278:24976-24985.

Dickey AS, Strack S (2011) PKA/AKAP1 and PP2A/B $\beta 2$ regulate neuronal morphogenesis via Drp1 phosphorylation and mitochondrial bioenergetics. J Neurosci 31:15716-15726.

Flippo KH, Gnanasekaran A, Perkins GA, Ajmal A, Merrill RA, Dickey AS, Taylor SS, McKnight GS, Chauhan AK, Usachev YM, Strack S (2018) AKAP1 protects from cerebral ischemic stroke by inhibiting Drp1-dependent mitochondrial fission. J Neurosci 38:8233-8242.

Grohm J, Kim SW, Mamrak U, Tobaben S, Cassidy-Stone A, Nunnari J, Plesnila N, Culmsee C (2012) Inhibition of Drp1 provides neuroprotection in vitro and in vivo. Cell Death Differ 19:1446-1458.

Holmes SE, O'Hearn EE, McInnis MG, Gorelick-Feldman DA, Kleiderlein JJ, Callahan C, Kwak NG, Ingersoll-Ashworth RG, Sherr M, Sumner AJ, Sharp AH, Ananth U, Seltzer WK, Boss MA, Vieria-Saecker AM, Epplen JT, Riess O, Ross CA, Margolis RL (1999) Expansion of a novel CAG trinucleotide repeat in the 5 'region of PPP2R2B is associated with SCA12. Nat Genet 23:391-392.

Kashatus JA, Nascimento A, Myers LJ, Sher A, Byrne FL, Hoehn KL, Counter CM, Kashatus DF (2015) Erk2 phosphorylation of Drp1 promotes mitochondrial fission and MAPK-driven tumor growth. Mol Cell 57:537-551.

Kawano Y, Tamura A, Kadota J (2006) Klippel-Feil syndrome accompanied by an aneurysm of the non-coronary sinus of Valsalva. Intern Med 45:1191-1192.

Li Y, Wang P, Wei J, Fan R, Zuo Y, Shi M, Wu H, Zhou M, Lin J, Wu M, Fang X, Huang Z (2015) Inhibition of Drp1 by Mdivi-1 attenuates cerebral ischemic injury via inhibition of the mitochondria-dependent apoptotic pathway after cardiac arrest. Neuroscience 311:67-74.

Merrill RA, Slupe AM, Strack S (2013) N-terminal phosphorylation of protein phosphatase $2 \mathrm{~A} / \mathrm{B} \beta 2$ regulates translocation to mitochondria, dynamin-related protein 1 dephosphorylation, and neuronal survival. FEBS J 280:662-673.

Nicholls DG, Budd SL (1998) Mitochondria and neuronal glutamate excitotoxicity. Biochim. Biophys. Acta 1366:97-112.

Nicholls DG, Johnson-Cadwell L, Vesce S, Jekabsons M, Yadava N (2007) Bioenergetics of mitochondria in cultured neurons and their role in glutamate excitotoxicity. J Neurosci Res 85:3206-3212.

Qi X, Disatnik MH, Shen N, Sobel RA, Mochly-Rosen D (2011) Aberrant mitochondrial fission in neurons induced by protein kinase $\mathrm{C}\{$ delta $\}$ under oxidative stress conditions in vivo. Mol Biol Cell 22:256-265.

Ramos-Cabrer P, Campos F, Sobrino T, Castillo J (2011) Targeting the ischemic penumbra. Stroke 42:S7-S11.

Schnizler K, Shutov LP, Van Kanegan MJ, Merrill MA, Nichols B, McKnight GS, Strack S, Hell JW, Usachev YM (2008) Protein kinase A anchoring via AKAP150 is essential for TRPV1 modulation by forskolin and prostaglandin E2 in mouse sensory neurons. J Neurosci 28:4904-4917.

Shalbuyeva N, Brustovetsky T, Bolshakov A, Brustovetsky N (2006) Calciumdependent spontaneously reversible remodeling of brain mitochondria. J Biol Chem 281:37547-37558.

Slupe AM, Merrill RA, Flippo KH, Lobas MA, Houtman JC, Strack S (2013) A calcineurin docking motif (LXVP) in dynamin-related protein 1 contributes to mitochondrial fragmentation and ischemic neuronal injury. J Biol Chem 288:12353-12365.

Strack S, Wilson TJ, Cribbs JT (2013) Cyclin-dependent kinases regulate splice-specific targeting of dynamin-related protein 1 to microtubules. J Cell Biol 201:1037-1051.

Strack S, Zaucha JA, Ebner FF, Colbran RJ, Wadzinski BE (1998) Brain protein phosphatase $2 \mathrm{~A}$ : developmental regulation and distinct cellular and subcellular localization by B subunits. J Comp Neur 392:515527.

Taguchi N, Ishihara N, Jofuku A, Oka T, Mihara K (2007) Mitotic phosphorylation of dynamin-related GTPase Drp1 participates in mitochondrial fission. J Biol Chem 282:11521-11529. 
Traystman RJ (2003) Animal models of focal and global cerebral ischemia. ILAR J 44:85-95.

Traystman RJ, Kirsch JR, Koehler RC (1991) Oxygen radical mechanisms of brain injury following ischemia and reperfusion. J Appl Physiol. 71:11851195.

Uo T, Dworzak J, Kinoshita C, Inman DM, Kinoshita Y, Horner PJ, Morrison RS (2009) Drp1 levels constitutively regulate mitochondrial dynamics and cell survival in cortical neurons. Exp Neurol 218:274285.

Vesce S, Kirk L, Nicholls DG (2004) Relationships between superoxide levels and delayed calcium deregulation in cultured cerebellar granule cells exposed continuously to glutamate. J Neurochem 90:683-693.
Wang X, Leverin AL, Han W, Zhu C, Johansson BR, Jacot E, Ten VS, Sims NR, Hagberg H (2011) Isolation of brain mitochondria from neonatal mice. J Neurochem 119:1253-1261.

Yadava N, Nicholls DG (2007) Spare respiratory capacity rather than oxidative stress regulates glutamate excitotoxicity after partial respiratory inhibition of mitochondrial complex I with rotenone. J. Neurosci 27:7310-7317.

Young KW, Pinon LG, Bampton ET, Nicotera P (2010) Different pathways lead to mitochondrial fragmentation during apoptotic and excitotoxic cell death in primary neurons. J Biochem Mol Toxicol 24:335-341.

Zhao YX, Cui M, Chen SF, Dong Q, Liu XY (2014) Amelioration of Ischemic Mitochondrial Injury and Bax-Dependent Outer Membrane Permeabilization by Mdivi-1. CNS Neurosci Ther 20:528-538. 